\title{
The estimation of body density in rugby union football players
}

\author{
W. Bell PhD \\ Faculty of Education and Sport, Cardiff Institute of Higher Education, Cyncoed, Cardiff, UK
}

\begin{abstract}
The general regression equation of Durnin and Womersley for estimating body density from skinfold thicknesses in young men, was examined by comparing the estimated density from this equation, with the measured density of a group of 45 rugby union players of similar age. Body density was measured by hydrostatic weighing with simultaneous measurement of residual volume. Additional measurements included stature, body mass and skinfold thicknesses at the biceps, triceps, subscapular and suprailiac sites. The estimated density was significantly different from the measured density $(P<0.001)$, equivalent to a mean overestimation of relative fat of approximately $4 \%$. A new set of prediction equations for estimating density was formulated from linear regression using the logarithm of single and sums of skinfold thicknesses. Equations were derived from a validation sample $(n=22)$ and tested on a crossvalidation sample $(n=23)$. The standard error of the estimate (s.e.e.) of the equations ranged from 0.0058 to $0.0062 \mathrm{~g} \mathrm{ml}^{-1}$. The derived equations were successfully crossvalidated. Differences between measured and estimated densities were not significant $(P>0.05)$, total errors ranging from 0.0067 to $0.0092 \mathrm{~g} \mathrm{ml}^{-1}$. An exploratory assessment was also made of the effect of fatness and aerobic fitness on the prediction equations. The equations should be applied to players of similar age and playing ability, and for the purpose of identifying group characteristics. Application of the equations to individuals may give rise to errors of between $-3.9 \%$ to $+2.5 \%$ total body fat in two-thirds of cases.
\end{abstract}

Keywords: body density, body composition, prediction, rugby players

Equations for the prediction of body density, and consequently body composition, have, in the main, been found to be specific to the population from which they have been derived ${ }^{1}$. Thus equations have tended to be age, gender and population specific.

In recent years attention has been directed towards overcoming specificity, and to the formulation of equations which would have a more general application $^{1-7}$. Unfortunately, many of these equations have performed unsatisfactorily, in that they have produced biased estimates of body density when applied to groups of different ages and fatness. The reasons for this are both biological ${ }^{8-12}$ and methodologi$\mathrm{cal}^{1,13,14}$.

Address for correspondence: W. Bell, Faculty of Education and Sport, Cardiff Institute of Higher Education, Cyncoed, Cardiff CF2 6XD, UK
Because of the considerable variation in body composition within and between athletic groups, it seems doubtful whether any single equation, general or specific, would be suitable for use with all athletic populations. This has resulted in the formulation of a number of sports-specific equations ${ }^{15-19}$. At the same time, a number of studies have validated existing equations, both general and specific, for use with practising athletes ${ }^{20-22}$.

A frequently used set of equations for estimating the body composition of athletes in the UK, are those of Durnin and Womersley ${ }^{3}$. Based on age and gender, these equations use single, and multiple combinations of the logarithm of the biceps, triceps, subscapular and suprailiac skinfolds. The most commonly used equation employs the logarithm of the sum of the four skinfolds.

Since validity is the single most important factor influencing the usefulness of a regression equation, it is necessary to identify the extent to which a prediction equation estimates body density in groups of subjects other than that from which it was derived. The lack of suitable equations for use with particular sports has led investigators, and practitioners, to depend upon generalized equations such as those of Durnin and Womersley ${ }^{3}$. In these circumstances it is essential to know how well the equations perform. As far as is known, there are no validated equations for estimating body density in rugby union football players, and generalized equations do not appear to have been crossvalidated for this group of athletes.

The purpose of the present study, therefore, was to examine the Durnin and Womersley ${ }^{3}$ equation for young men (20-29 years), to identify its degree of effectiveness when used with rugby union players ${ }^{23-}$ 24. A comparison was made of the estimated density from the Durnin and Womersley ${ }^{3}$ equation, with the measured density of a group of rugby union football players of similar age. The equation did not, in fact, estimate body density accurately, thus a set of new equations was derived and crossvalidated.

\section{Materials and methods}

Subjects were international and first-class players ranging in age from 19 to 27 years; there were 34 forwards and 11 backs $(n=45)$. To provide a sample of players with a sufficiently wide range of body densities $\left(1.0526\right.$ to $\left.1.0898 \mathrm{~g} \mathrm{ml}^{-1}\right)$ and body fat 
(4-20\%) to validate the equation of Durnin and Womersley $^{3}$, the data for forwards and backs were pooled.

\section{Anthropometry and body density}

Anthropometric measurements were made according to the recommendations of Weiner and Lourie ${ }^{25}$ using the Harpenden range of equipment. Stature was measured to the nearest $0.1 \mathrm{~cm}$ with a fixed stadiometer and body mass to the closest $0.1 \mathrm{~kg}$ on a beam balance. Skinfold thicknesses were recorded to the nearest $0.1 \mathrm{~mm}$ on the left side of the body at the biceps, triceps, subscapular and suprailiac sites.

Body density was determined by hydrostatic weighing. Each subject was weighed in water maintained to within one degree of $35^{\circ} \mathrm{C}$. A sufficient number of trials was made to ensure a plateau of at least three readings, the mean being used as the final underwater weight. Duplicate measurements were made of residual volume at the time of underwater weighing using the closed-circuit oxygen rebreathing technique ${ }^{26}$. The contents of the rebreathing bag were analysed for oxygen and carbon dioxide (Beckman Instruments), nitrogen being obtained by difference. Body fat was calculated using the equation of $\mathrm{Siri}^{27}$. Fat-free mass (FFM) was derived by the subtraction of body fat from body mass.

All measurements in the study were made by one experienced observer. Within-observer reproducibility is reported as the technical error of measurement $\left({ }^{2} \sqrt{ } \Sigma d^{2} / 2 n\right)$. For height the value was $1.1 \mathrm{~mm}$ and for body mass $0.03 \mathrm{~kg}$. Skinfolds ranged from $0.14 \mathrm{~mm}$ for subscapular to $0.21 \mathrm{~mm}$ for the triceps. Underwater weight was $0.03 \mathrm{~kg}$ and residual volume $54 \mathrm{ml}$.

\section{The Durnin and Womersley equation}

The equation validated was

$$
D=1.1631-0.0632(\log X)
$$

where $D=$ estimated body density; $X=$ the sum of the biceps, triceps, subscapular and suprailiac skinfolds.

The equation was derived from 92 subjects between the ages of 20-29 years having a mean (range) density of $1.064(1.016-1.087) \mathrm{g} \mathrm{ml}^{-1}$ and a mean (range) fat content of $15(5-38) \%$. Subjects had been selected to represent a variety of body types and included volunteers from health clubs, obesity clinics and sports organizations.

\section{Formulation and crossvalidation of new equations}

Subjects were randomly assigned to a validation sample $(n=22)$ and a crossvalidation sample $(n=$ $23)$. The two samples did not differ significantly in age, height, body mass or body composition $(P>0.05)$. Prediction equations were derived from the validation sample and tested on the crossvalidation sample.

Linear regression equations were formulated to estimate body density from the logarithm of single, and combinations of the sums of two or more skinfold thicknesses. The logarithmic transform of
Table 1. Equations for estimating body density from the logarithm of various combinations of skinfold thicknesses

\begin{tabular}{llll}
\hline Skinfolds & Regression equation & s.e.e. & $\mathrm{R}^{2}$ \\
\hline $\mathrm{B}+\mathrm{T}+\mathrm{SI}$ & $D=1.16037-0.06155$ (log $\sum$ skinfolds) & 0.0058 & 69.2 \\
$\mathrm{~B}+\mathrm{T}+\mathrm{SS}$ & $D=1.18101-0.07788$ (log $\sum$ skinfolds) & 0.0060 & 66.5 \\
$\mathrm{~B}+\mathrm{TS}+\mathrm{SS}+\mathrm{SI}$ & $D=1.17373-0.06422$ (log $\sum$ skinfolds) & 0.0061 & 65.6 \\
$\mathrm{~B}+\mathrm{T}$ & $D=1.14856-0.06749$ (log $\sum$ skinfolds) & 0.0062 & 64.4 \\
$\mathrm{~T}+\mathrm{SI}$ & $D=1.14458-0.05394$ (log $\Sigma$ skinfolds) & 0.0062 & 63.7 \\
\hline
\end{tabular}

s.e.e., standard error of the estimate; $R^{2}$, coefficient of correlation squared; $D$, estimated body density $\left(\mathrm{g} \mathrm{ml}^{-1}\right)$; B, biceps; T, triceps; SS, subscapular; SI, suprailiac skinfolds

the skinfold is preferred to the raw measurement for two reasons; first, because the frequency distribution of most skinfold measurements is skewed and second, because the relationship of body density to skinfold thickness may not be rectilinear ${ }^{3,7}$. The use of age as an independent variable was not included in the regression models because of the already restricted age range of the subjects. Those equations with the smallest standard errors of the estimate (s.e.e.) were crossvalidated by assessing the significance of the difference between the measured and predicted densities and the correlations between them, and a comparison of the standard deviations, standard errors of the estimate, and total error ${ }^{1,14}$

An exploratory analysis was also made of the effect of levels of fatness and fitness of players as a whole, on the regression equations ${ }^{7}$. The crossvalidation sample was divided into lower $(n=11)$ and upper groups $(n=12)$ on the basis of measured density and estimated oxygen uptake. Body density was then estimated for both groups from the regression equations in Table 1. Estimated maximal oxygen uptake was available from linear extrapolation of $\mathrm{VO}_{2}$ and heart rate in some subjects, and from a progressive shuttle run test in others ${ }^{28}$.

\section{Statistical analyses}

A paired Student's $t$ test was employed to assess the significance of the difference between measured and estimated densities, and an independent Student's $t$ test to compare the measured density and estimated densities in crossvalidation. Pearson product-moment correlations and linear regression equations were computed using standard procedures ${ }^{29}$. All computations were carried out using the Minitab interactive statistical package (Data Tech Industries, Valley Forge, Pennsylvania, USA).

\section{Results}

\section{Characteristics of subjects}

Table 2 shows the descriptive characteristics for the original sample of 45 players. The frequency distribution for body density in $0.01 \mathrm{~g} \mathrm{ml}^{-1}$ class intervals, beginning $1.050-1.059$, was $27 \%, 24 \%, 33 \%$ and $16 \%$. Of the sample, $84 \%$ were found between 1.050 and $1.080 \mathrm{~g} \mathrm{ml}^{-1}$, thus there was a clear positive skew. The normal probability plot yielded a correla- 
tion of 0.98 , a figure above the critical value required for normality. The logarithm of single and summed skinfolds was found to correlate more highly with body density $(-0.61$ to -0.80$)$ than raw skinfolds $(-0.57$ to -0.77$)$, although differences were not significant $(P>0.05)$.

\section{Validation of the Durnin and Womersley equation}

The measured density of the 45 subjects and the density estimated from the Durnin and Womersley equation are given in Table 3, together with the derived values for body composition. Differences between the measured and estimated values were significant for all variables $(P<0.001)$.

The validation statistics of the equation included a comparison of the measured and estimated densities (1.0695 versus $1.0599 \mathrm{~g} \mathrm{ml}^{-1}, P<0.001$ ) and their standard deviations $\left(0.0105\right.$ versus $\left.0.0082 \mathrm{~g} \mathrm{ml}^{-1}\right)$, the mean difference $\left(0.0095 \mathrm{~g} \mathrm{ml}^{-1}\right)$, standard error of the

Table 2. Age, physical characteristics and skinfold thicknesses of the original sample of 45 rugby players

\begin{tabular}{lcc}
\hline & Mean(s.d.) & Range \\
\hline Age (years) & $22.1(2.0)$ & $18.9-26.9$ \\
Height (cm) & $182.1(8.0)$ & $162.9-200.0$ \\
Body mass $(\mathrm{kg})$ & $89.95(11.7)$ & $66.45-120.0$ \\
Body density $\left(\mathrm{g} \mathrm{ml}^{-1}\right)$ & $1.0695(0.0105)$ & $1.0526-1.0898$ \\
Biceps $(\mathrm{mm})$ & $5.5(1.6)$ & $3.1-10.4$ \\
Triceps $(\mathrm{mm})$ & $11.0(4.0)$ & $5.0-28.0$ \\
Subscapular $(\mathrm{mm})$ & $12.7(3.5)$ & $5.6-20.0$ \\
Suprailiac $(\mathrm{mm})$ & $15.5(6.9)$ & $6.3-30.8$ \\
\hline
\end{tabular}

Table 3. Comparison of measured and estimated body density $(n=45)$, derived components of body composition, and validation statistics of the estimations

\begin{tabular}{lcc}
\hline & $\begin{array}{c}\text { Measured } \\
\text { Mean(s.d.) }\end{array}$ & $\begin{array}{c}\text { Durnin and Womersley } \\
\text { Mean(s.d.) }\end{array}$ \\
\hline Density $\left(\mathrm{g} \mathrm{m}^{-1}\right)$ & $1.0695(0.0105)$ & $\begin{array}{c}1.0599(0.0082)^{*} \\
\text { TBF (\%) }\end{array}$ \\
FFM (\%) & $12.89(4.5)$ & $17.03(3.6)^{*}$ \\
TBF (kg) & $87.11(4.5)$ & $82.97(3.6)^{*}$ \\
FFM (kg) & $11.80(4.8)$ & $15.48(4.4)^{*}$ \\
& $78.15(9.3)$ & $74.47(8.9)^{*}$ \\
\hline
\end{tabular}

${ }^{*} P<0.001 ; T B F$, total body fat; FFM, fat-free mass; mean difference $=$ $0.0095 \mathrm{~g} \mathrm{ml}^{-1}$; s.e.e. (s.d. measured density $\left.\times \sqrt{ }\left(1-r^{2}\right)\right)=0.0063 \mathrm{~g} \mathrm{ml}^{-1}$. total error $\left(\sqrt{ } \Sigma(\text { estimated }- \text { measured density })^{2} / \mathrm{N}\right)=0.0114 \mathrm{~g} \mathrm{ml}^{-1}$. correlation of measured and estimated densities $=0.80(P<0.001)$ estimate $\left(0.0063 \mathrm{~g} \mathrm{ml}^{-1}\right)$, total error $\left(0.0114 \mathrm{~g} \mathrm{ml}^{-1}\right)$ and the correlation between measured and estimated densities $(0.80, P<0.001)$. The difference between the actual density and the estimated density using the Durnin and Womersley equation, was equivalent to a mean overestimation of relative fat of approximately $4 \%$.

\section{Formulation and crossvalidation of prediction equations}

In the validation sample, as in the original sample, the correlations between body density and the logarithm of single and summed skinfolds were higher $(-0.73$ to -0.81$)$ than those between body density and the raw skinfolds $(-0.66$ to -0.80$)$. Using body density as the dependent variable and the logarithm of skinfold thicknesses as independent variables, linear regression equations were derived using all possible combinations of skinfold thicknesses. Table 1 lists the five regression equations which gave the lowest s.e.e. values.

Table 4 shows the crossvalidation statistics for the equations given in Table 1. Differences between the measured and estimated densities were not significant $(P>0.05)$, and were equivalent to a difference of between $-0.3 \%$ to $-1.4 \%$ total body fat (TBF) from the measured value of $12.5 \%$. All correlations were reasonably high, ranging from 0.64 to $0.79(P<0.001)$. As anticipated the standard deviations of the estimated densities $\left(0.0080\right.$ to $\left.0.0098 \mathrm{~g} \mathrm{ml}^{-1}\right)$ were lower than that of the measured density $(0.0109 \mathrm{~g}$ $\mathrm{ml}^{-1}$ ).

Table 5 shows the effect of levels of fatness and fitness on the estimation of body density in the crossvalidation sample. Measured and estimated body density differed significantly $(P<0.05)$ in four of the five equations for fatness in the upper group. The estimated density was consistently and significantly less than the measured density $(P<0.05)$, suggesting that the equations may have specificity for fatness. Density values were similarly overestimated in the upper fitness group, although, here, the differences were not significant $(P>0.05)$.

\section{Discussion}

In recent years the pursuit of improved performance by athletes has led to the quantification and evaluation of conditioning and training programmes. This has been accompanied by an increase in the use

Table 4. Crossvalidation of the derived equations using the logarithm of skinfold thicknesses as the predictor variable

\begin{tabular}{|c|c|c|c|c|c|}
\hline Skinfolds & Estimated density* mean(s.d.) & Mean difference & s.e.e. & Total error & Correlation coefficient ${ }^{\dagger}$ \\
\hline$B+T+S I$ & $1.0695(0.0087)$ & 0.0008 & 0.0071 & 0.0069 & 0.76 \\
\hline $\mathrm{B}+\mathrm{T}+\mathrm{SS}+\mathrm{SI}$ & $1.0693(0.0085)$ & 0.0011 & 0.0067 & 0.0067 & 0.79 \\
\hline$B+T$ & $1.0670(0.0093)$ & 0.0033 & 0.0084 & 0.0092 & 0.64 \\
\hline $\mathrm{T}+\mathrm{SI}$ & $1.0697(0.0080)$ & 0.0007 & 0.0067 & 0.0066 & 0.79 \\
\hline Measured density & $1.0704(0.0109)$ & & & & \\
\hline
\end{tabular}

${ }^{*}$ Measured and estimated densities not significantly different $(P>0.05) ;{ }^{\dagger}$ all coefficients of correlation significant at $P<0.001 ; \mathrm{B}$, biceps; $\mathrm{T}$, triceps;

SS, subscapular; SI, suprailiac 
Table 5. The estimation of body density of the crossvalidation sample divided into upper and lower groups on the basis of measured density and estimated aerobic fitness $\left(\dot{V}_{\mathrm{O}_{2} \text { max }}\right)$ using the prediction equations in Table 1

\begin{tabular}{|c|c|c|c|c|c|c|}
\hline \multirow[b]{2}{*}{ Skinfolds } & \multicolumn{3}{|c|}{ Lower group $(\mathrm{n}=11)$} & \multicolumn{3}{|c|}{ Upper group $(n=12)$} \\
\hline & Mean difference & Total error & Correlation & Mean difference & Total error & Correlation \\
\hline $\begin{array}{l}\text { Density }\left(\mathrm{g} \mathrm{ml}^{-1}\right)^{*} \\
B+T+S \mathrm{I} \\
B+T+S S \\
B+T+S S+S I \\
B+T \\
T+S I\end{array}$ & $\begin{array}{l}-0.0021 \\
-0.0004 \\
-0.0020 \\
-0.0005 \\
-0.0027\end{array}$ & $\begin{array}{c}610(0.0042) \\
0.0073 \\
0.0071 \\
0.0069 \\
0.0071 \\
0.0070\end{array}$ & $\begin{array}{l}0.11 \\
0.31 \\
0.13 \\
0.35 \\
0.13\end{array}$ & $\begin{array}{l}0.0035 \\
0.0055 t \\
0.0039 t \\
0.0068 t \\
0.0038 t\end{array}$ & $\begin{array}{c}790(0.0073) \\
0.0065 \\
0.0091 \\
0.0064 \\
0.0107 \\
0.0062\end{array}$ & $\begin{array}{l}0.63 t \\
0.57 \\
0.69 t \\
0.34 \\
0.72 t\end{array}$ \\
\hline 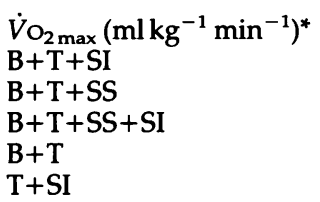 & $\begin{array}{r}-0.0003 \\
0.0006 \\
-0.0002 \\
0.0005 \\
-0.0004\end{array}$ & $\begin{array}{c}42.5(6.0) \\
0.0041 \\
0.0070 \\
0.0045 \\
0.0072 \\
0.0040\end{array}$ & $\begin{array}{l}0.91 \S \\
0.78 \ddagger \\
0.89 \S \\
0.76 \ddagger \\
0.91 \S\end{array}$ & $\begin{array}{r}-0.0028 \\
0.0012 \\
-0.0019 \\
0.0016 \\
-0.0027\end{array}$ & $\begin{array}{r}53.3(3.0) \\
0.0072 \\
0.0065 \\
0.0065 \\
0.0080 \\
0.0069\end{array}$ & $\begin{array}{l}0.70 \dagger \\
0.74 \ddagger \\
0.74 \ddagger \\
0.62 \dagger \\
0.73 t\end{array}$ \\
\hline
\end{tabular}

*Values are mean(s.d.); $†, P<0.05 ; \ddagger, P<0.01 ; \S, P<0.001 ; B$, biceps; T, triceps; SS, subscapular; SI, suprailiac

of field tests for assessment purposes. Since body composition is an important variable in the constitution of an athlete, often providing a baseline for the attainment of optimal fitness, the prediction of whole-body estimates of fat and FFM has been attractive.

It is now well established that most studies yield results which are population specific, being influenced by factors such as age, gender, racial background and the characteristics of fatness and fitness $1,3,5,7,30$. On these grounds, it seems doubtful whether a generalized equation would be suitable for the variety of athletic groups that exists. Not only is there a difference between the general and athletic population in factors such as age, fatness and fitness, but there is likely to be a difference both between and within the sporting groups themselves.

The Durnin and Womersley ${ }^{3}$ equation was found to be inaccurate in estimating the body density of rugby players. The estimated density $\left(1.0599 \mathrm{~g} \mathrm{ml}^{-1}\right)$ was found to be significantly less $(P<0.001)$ than the measured density $\left(1.0695 \mathrm{~g} \mathrm{ml}^{-1}\right)$. The difference was equivalent to a mean overestimation of relative fat, and consequently an underestimation of FFM, of approximately $4 \%$. This value is similar in magnitude to other Durnin and Womersley equations which have been crossvalidated ${ }^{20}$. Individual deviations ranged from $-3 \%$ to $+10 \%$. The reason for the difference between measured and estimated densities (Table 3) was probably due to the higher mean body density of this group of individuals compared with those of a similar age in the normal population.

As a rule the s.e.e. values of prediction equations in athletic groups are usually smaller than those of non-athletic groups, due to their more homogeneous nature ${ }^{1}$. The present s.e.e. values (Table 1) ranged from 0.0058 to $0.0062 \mathrm{~g} \mathrm{ml}^{-1}$ and compared well with those of other general and athletic groups ${ }^{1,7,15,17}$. There is, in fact, little to choose between the five equations. The measured density of $1.0704 \mathrm{~g} \mathrm{ml}^{-1}$ was estimated within the range 1.0677 to $1.0697 \mathrm{~g} \mathrm{ml}^{-1}$ (Table 4), which is equivalent to a mean difference of between $-0.3 \%$ and $-1.4 \%$ TBF from the measured fat value.

The crossvalidation statistics (Table 4) showed good agreement between body density estimated from the five equations and the measured value, the s.e.e. values in the crossvalidation sample being slightly higher than those of the validation sample (Table 1). The total error, which is an expression of the s.e.e. and the mean difference between predicted and estimated densities, varied from 0.0066 to $0.0092 \mathrm{~g} \mathrm{ml}^{-1}$. Values of this magnitude are in the range of those previously reported ${ }^{1,5,7}$.

Measured and estimated densities due to fatness (Table 5) were significantly different $(P<0.05)$ in four of the five equations in the upper group. This suggests that even within a given sport, it is possible for equations to have specificity for fatness ${ }^{15,17}$. A similar finding by Norgan and Ferro-Luzzi ${ }^{7}$ led them to doubt whether, in fact, general equations could be drawn up for groups of widely differing fatness. Correlations were found to be moderate in the upper group (0.34 to 0.72 ) and weak in the lower group $(0.11$ to 0.35$)$. The poorer correlations of the lower group are probably due to the restricted density range, which was only about half that of the upper group.

Differences in density arising from high and low levels of aerobic fitness (Table 5) were not significant $(P>0.05)$, confirming a lack of specificity due to fitness within the range of measured values. Generally speaking, body density was overestimated in both the high and the low fitness groups, the mean differences and total errors being smaller in the low fitness group. The correlations between measured and estimated densities ( 0.62 to 0.91$)$ were significant in both groups $(P<0.05$ to $P<0.001)$. The size of the samples in the analysis of fatness and fitness on the regression equations were small $(n=11)$; consequently the results should be regarded as provisional.

The s.e.e. of TBF from body density determined by hydrostatic weighing is of the order of $2-3 \%^{31}$. In a specific population, the s.e.e. due to biological 
variability alone has been estimated to be within the range of $0.004-0.006 \mathrm{~g} \mathrm{ml}^{-1}$ (Reference 1). In the present set of equations the s.e.e. averaged $0.0075 \mathrm{~g}$ $\mathrm{ml}^{-1}$, which is about $17 \%$ of the density range, so there is still a degree of error associated with prediction. External crossvalidation of the prediction equations using subjects of a similar level of playing ability would substantiate their applicability. This is an important consideration, since the use of prediction equations in the same sport, but at a different level of playing ability, has been found to be unsatisfactory ${ }^{21}$.

There are a number of factors arising from biological variation which are likely to contribute to specificity. In the estimation of body density from skinfold thicknesses these will include the density of the $\mathrm{FFM}^{8-10}$, the proportion of fat situated subcutaneously ${ }^{3,32}$, the pattern of subcutaneous tissue distribution $^{33}$, skin thickness and skinfold compressibility $^{34}$. These factors in turn may well be influenced by differences in age, gender, fatness and fitness ${ }^{3,5,7}$. As a consequence, anomalous results may sometimes occur; for example, the exceptionally low levels of fat in élite distance runners ${ }^{35}$ and the negative fat values found in Canadian football players ${ }^{36}$.

Monitoring the progress of athletes during training usually requires serial measurements taken at prespecified occasions. For body composition this is often achieved by measuring skinfold thicknesses and estimating whole body composition from prediction equations. The attraction of this is the apparent simplicity and convenience with which it is carried out, and in understanding and interpreting the result. However, there is the assumption that changes in skinfold thickness accurately reflect alterations in body composition. Wilmore et al. ${ }^{37}$ found the correlations between actual and predicted changes in body composition low to moderate. Cisar et al. ${ }^{38}$, on the other hand, found them to be much higher; however, in crossvalidating 24 equations, only four were identified as having the ability to predict accurately changes in body composition due to training.

It is clear that more accurate estimates of whole body composition for rugby players of first-class status between the ages of 19 and 27 years, can be obtained by using specific equations to estimate body density, rather than the generalized equation of Durnin and Womersley ${ }^{3}$. Five internally crossvalidated equations are presented for use, together with a provisional assessment of the effect of fatness and aerobic fitness on the estimation of body density. The regression models should be applied to rugby players with characteristics similar to those described, and for the prime purpose of estimating group statistics. Application of the equations to individuals in the crossvalidation sample gave rise to errors ranging between $-3.9 \%$ and $+2.5 \%$ body fat in two-thirds of cases. Until such time that measurement techniques and multicomponent equations allow for a more accurate prediction of individual values ${ }^{12}$, athletes and coaches may prefer to use skinfold thicknesses directly, although even this procedure may require some caution when comparing estimates of fatness among different subjects ${ }^{34}$.

\section{References}

1 Lohman TG. Skinfolds and body density and their relation to body fatness: a review. Hum Biol 1981; 53: 181-225.

2 Sloan AW. Estimation of body fat in young men. J Appl Physiol 1967; 23: 311-15.

3 Durnin JVGA, Womersley J. Body fat assessed from total body density and its estimation from skinfold thickness: measurements on 481 men and women from 16 to 72 years. $\mathrm{Br}$ J Nutr 1974; 32: 77-97.

4 Weltman A, Katch VL. A non population-specific method for predicting total body volume and percent fat. Hum Biol 1978; 50: 151-8.

5 Jackson AS, Pollock ML. Generalized equations for predicting body density in men. Br J Nutr 1978; 40: 497-504.

6 Jackson AS, Pollock ML, Ward A. Generalized equations for predicting body density of women. Med Sci Sports Exerc 1980; 12: 175-182.

7 Norgan NG, Ferro-Luzzi A. The estimation of body density in men: are general equations general? Ann Hum Biol 1985; 12: $1-15$.

8 Womersley J, Durnin JVGA, Boddy K, Mahaffy M. Influence of muscular development, obesity and age on the fat-free mass of adults. J Appl Physiol 1976; 41: 223-9.

9 Clarys JP, Martin AD, Drinkwater DT. Gross tissue weights in the human body by cadaver dissection. Hum Biol 1984; 56: 459-73.

10 Clarys JP, Martin AD. The concept of the adipose tissue-free mass. Communication at Euro-Nutr Workshop on Human Body Composition. London, UK: Ciba Foundation, 1985.

11 Clarys JP, Martin AD, Drinkwater DT, Marfell-Jones MJ. The skinfold: myth and reality. J Sports Sci 1987; 5: 3-33.

12 Lohman TG. Advances in Body Composition Assessment. Champaign, Illinois, USA: Human Kinetics, 1992.

13 Jackson AS, Pollock ML. Prediction accuracy of body density, lean body weight, and total body volume equations. Medicine and Science in Sports 1977; 9: 197-201.

14 Katch FI, Katch VL. Measurement and prediction errors in body composition assessment and the search for the perfect prediction equation. Res Quart Exerc Sport 1980; 51: 249-60.

15 Forsyth HL, Sinning WE. The anthropometric estimation of body density and lean body weight of male athletes. Medicine and Science in Sports 1973; 5: 174-80.

16 Sinning WE. Body composition assessment of college wrestlers. Medicine and Science in Sports 1974; 4: 139-45.

17 Wickkiser JD, Kelly JM. The body composition of a college football team. Medicine and Science in Sports 1975; 7: 199-202.

18 White J, Mayhew JL, Piper FC. Prediction of body composition in college football players. J Sports Med Phys Fitness 1980; 20: 317-24.

19 Mayhew JL, Piper FC, Holmes JA. Prediction of body density, fat weight, and lean body mass in male athletes. J Sports Med Phys Fitness 1981; 21: 383-9.

20 Sinning WE, Dolny DG, Little KD, Cunningham LN, Racaniello A, Siconolfi SF, Sholes JL. Validity of "generalized" equations for body composition analysis in male athletes. Med Sci Sports Exerc 1985; 17: 124-30.

21 Smith JF, Mansfield ER. Body composition prediction in University football players. Med Sci Sports Exerc 1984; 16: 398-405.

22 Thorland WG, Johnson GO, Tharp GD, Fagot TG, Hammer RW. Validity of anthropometric equations for the estimation of body density in adolescent athletes. Med Sci Sports Exerc 1984; 16: 77-81.

23 Bell W. Body composition of rugby union football players. $\mathrm{Br}$ J Sports Med 1979; 13: 19-23.

24 Bell W. Body composition and maximal aerobic power of rugby union forwards. I Sports Med Phys Fitness 1980; 20: 447-51.

25 Weiner JS, Lourie JA. Practical Human Biology. London: Academic Press, 1981.

26 Durnin JVGA, Rahaman MM. The measurement of the amount of fat in the human body from measurements of skinfold thicknesses. Br J Nutr 1967; 21: 681-9.

27 Siri WE. Body composition from fluid spaces and density: analysis of methods. In: Brozek J, Henschel A, eds. Techniques for Measuring Body Composition. Washington DC, USA: Nat Acad Sci, 1961, 223-44. 
28 Ramsbottom R, Brewer J, Williams C. A progressive shuttle run test to estimate maximal oxygen uptake. $\mathrm{Br} J$ Sports Med 1988; 22: 141-4.

29 Snedecor GW, Cochran WG. Statistical Methods. Iowa, USA: Iowa State University Press, 1967.

30 Vickery SR, Cureton KJ, Collins MA. Prediction of body density from skinfolds in black and white young men. Hum Biol 1988; 60: 135-49.

31 Womersley J, Durnin JVGA. A comparison of the skinfold method with extent of "overweight" and various weightheight relationships in the assessment of obesity. $\mathrm{Br} J$ Nutr 1977; 38: 271-84.

32 Davies PSW, Jones PRM, Norgan NG. The distribution of subcutaneous and internal fat in man. Ann Hum Biol 1986; 13: 189-92.

33 Brown WJ, Jones PRM. The distribution of body fat in relation to habitual activity. Ann Hum Biol 1977; 4: 537-50.
34 Martin AD, Drinkwater DT, Clarys JP, Daniel M, Ross WD. Effects of skin thickness and skinfold compressibility on skinfold thickness measurement. American Journal of Human Biology 1992; 4: 453-60.

35 Pollock ML, Gettman LR, Jackson A, Ayres J, Ward A, Linnerud AC. Body composition of elite class distance runners. Ann NY Acad Sci 1977; 301: 361-70.

36 Adams J, Mottola M, Bagnall KM, McFadden KD. Total body fat content in a group of professional football players. Canadian Journal of Applied Sport Sciences 1982; 7: 36-44.

37 Wilmore JH, Girandola RN, Moody DL. Validity of skinfold and girth assessment for predicting alterations in body composition. J Appl Physiol 1970; 29: 313-17.

38 Cisar CJ, Housh TJ, Johnson GO, Thorland WG, Hughes RA. Validity of anthropometric equations for determination of changes in body composition in adult males during training. J Sports Med Phys Fitness 1989; 29: 141-8. 